\title{
Electro-optics program at Indiana University of Pennsylvania
}

\section{Feng Zhou}

Feng Zhou, "Electro-optics program at Indiana University of Pennsylvania," Proc. SPIE 9664, Ninth International Topical Meeting on Education and Training in Optics and Photonics, 96640W (24 October 2005); doi: $10.1117 / 12.2207688$

Event: Ninth International Topical Meeting on Education and Training in Optics and Photonics, 2005, Marseille, France 
Ref ETOP030

\title{
Electro-Optics Program at Indiana University of Pennsylvania
}

\author{
Feng Zhou
}

Physics Department, Indiana University of Pennsylvania, 167 Northpointe Blvd., Freeport, PA 16229, Email: fzhou@iup.edu

\begin{abstract}
This paper reviews the new Electro-Optics (EO) program at Indiana University of Pennsylvania (IUP), launched in August 2002 . The Electro-Optics (EO) degree program is designed to train a wide range of students for entry into the rapidly-evolving photonics workforce by offering both 2year AAS/AS and 4-year BS degree. The more recent developments of the program are also outlined, including the high school outreach and visitation program, the proposed $2+2+2$ educational pathway to promote early participation of bright students in photonics-related disciplines, as well as the integration of nanotechnology into the core EO curriculum.
\end{abstract}

\section{Keywords}

electro-optics, photonics, nanophotonics, optics education, workforce development

\section{Introduction}

\section{Summary}

Founded in 1875, Indiana University of Pennsylvania (IUP) is a comprehensive university providing an intellectually challenging experience to nearly fourteen thousand students at the university's three campuses. As the largest one of the 14 universities within the Pennsylvania State System of Higher Education, IUP's academic offerings include more than a hundred undergraduate majors with a variety of internship and study abroad programs, more than forty master's degree programs, and eight doctoral degrees. The university mission statement indicates that "IUP serves students from across the nation and around the world by introducing them to and sustaining them in a culture of high aspiration and achievement so they may lead productive and meaningful lives."

The Physics Department at IUP has maintained a long tradition of high-quality graduate and undergraduate instructional and research programs. The Physics Department has built on this tradition by developing a brand new BS program in Applied Physics with Nano-manufacturing technology (NMT) and Electro-optics (EO) tracks, strengthening a respected MS Program in Physics, graduating a nationally significant number of secondary school physics teachers, and acquiring a wide range of state-of-the-art experimental and computational facilities. These factors have placed IUP in a unique position to offer several structured, rigorous, and intensive research/teaching programs in Applied Physics for motivated undergraduate students.

For many years, western Pennsylvania thrived economically on such industries as coal and steel. However, in recent decades the emphasis on these industries has shifted, resulting in an economic decline and a demographic shift for this once prosperous region. In order to regain prosperity, regional and state leaders have focused attention on the revitalization of the local 
economy and its workforce. To accomplish these goals, they have attracted a new emerging high-tech industry - Electro Optics (EO) - to the area. According to regional industry officials, western Pennsylvania needs to look to the future and pinpoint current industry niches if it wants to continue to build a technology base that would grow into economic generators.

As the result, the Armstrong County Board of Commissioners and the Armstrong County Industrial Development Authority are credited with the recent development of Northpointe Technology Center, a 925-acre technology park with an emphasis on attracting Electro-Optics and other high-tech related industries. Only 33 miles from Pittsburgh with easy access to major highways and the Pennsylvania Turnpike, Northpointe, located in Freeport, PA, has the infrastructure and economic incentives to attract and support global companies such as Boeing, DRS, and RAPT, as well as small start-up companies such as Armstrong Laser Technology, Sabeus Sensor Technology, and Caeacal, Inc, etc.

Focused on the revitalization of the local economy and its workforce, the Physics Department, IUP, launched its new joint AAS/AS/BS Electro-Optics (EO) degree Programs in August 2002, which is designed to educate a wide range of students for entry into the rapidly-evolving photonics workforce. The first option, an Associate of Applied Science degree (A.A.S. in ElectroOptics), is geared toward individuals seeking employment as senior technicians in the field. The second option, the Associate of Science degree (A.S. in Electro-Optics), has a larger concentration of liberal studies courses. With the A.S.E.O. degree the student has a choice of either going directly to work or to matriculate at IUP main campus and earn a B.S. degree in the Electro-Optics track in Applied Physics.

The two Associate Degrees in Electro-Optics, Associate in Applied Science in Electro-Optics (A.A.S.E.O.) and Associate in Science in Electro-Optics (A.S.E.O.) are located at the Northpointe Technology Center, Armstrong Campus, after the new building was completed in August 2005. The new location makes the program more connected to the industry and the local community, while providing our students with new classrooms and labs equipped with state-of-art equipment.

\section{Electro-optics at IUP}

The EO program offers 12 core courses to provide students with the necessary background to matriculate into high-tech positions. The first two years' studies which will satisfy the Associate degree requirements are outlined below.

\section{Semester I}

ENGL 101 College Writing

PHYS 100 Prelude to Physics

${ }^{1}$ COSC 101 Microbased Computer Literacy

EOPT 105 Computer Interfacing in E-O

EOPT 110 Geometric Optics

${ }^{1}$ Or COSC 201 Internet and Multimedia

\begin{tabular}{c} 
Credits \\
\hline 4 \\
3 \\
3 \\
3 \\
$\frac{3}{16}$
\end{tabular}

Proc. of SPIE Vol. $966496640 \mathrm{~W}-2$ 


\section{Semester II}

Social Science

${ }^{2}$ MATH 110 Elementary Functions

PHYS 115 Physics I for Electro-Optics

3

EOPT 120 Wave Optics

EOPT 125 Introduction to Electronics

3

4

2 Or MATH 121 Calculus I

\section{Semester III}

CHEM 111 General Chemistry I

PHYS 116 Physics II for Electro-Optics

MGMT 234 Introduction to Quality Control EOPT 210 Detection and Measurement

EOPT 220 Introduction to Lasers

Semester IV

Humanities Elective

3

SAFE 145 Workplace Safety Today and Tomorrow

3

EOPT 240 Fiber Optics

EOPT 250 High Vacuum Technology

EOPT 260 Industrial Applications of Lasers

The total credits are $63-64$, including $20-21$ credits of liberal studies:

\section{Minimum Liberal Studies Core - $16 \mathrm{hrs}$.}

\section{Courses in Program}

\section{Credits}

English Composition

Math

Humanities

Fine Arts

Natural Sciences

Social Sciences

Health / Wellness

Liberal Studies Elective
(4-7)

(3-4)

(3)

$(0-3)$

$(0-8)$

$(3-6)$

$(0-3)$

$(0)$
ENGL 101

MATH 110 or 121

Humanities Elective 3

CHEM 111

Social Science Elective 3

COSC 101 or 201

The 12 core courses of the EO program are listed in Table 1. 
Table 1 EO Program Core Courses

- $\quad$ EOPT 105 Introduction to Electronics

- EOPT 125 Computer Interfacing in Electro-Optics

- EOPT 110 Geometric Optics

- EOPT 120 Wave Optics

- PHYS 115 Physics I for Electro-Optics

- PHYS 116 Physics II for Electro-Optics

- EOPT 210 Detection and Measurement

- EOPT 220 Introduction to Lasers

- EOPT 240 Fiber Optics

- EOPT 250 High Vacuum Technology

- EOPT 260 Industrial Applications of Lasers

Each EO core course has one 3-hour laboratory per week during each semester. Hence students are provided with a rich hands-on laboratory experience utilizing state-of-the art electro-optic equipment. Some of these instruments are listed used by the EO students are listed in Table 2.

Table 2 EO Equipment in the Physics Department, IUP

- Optical Spectrum Analyzers (OSA) (400nm -1600nm)

- 20W Fiber coupled Semiconductor Laser and Power Supply

- High Power, Q-switched, frequency tripled, diode pumped Nd:YVO4 laser

- Flashlamp pumped Q-switched Nd:YAG laser

- Ar+ laser with multi-wavelength output

- Red, yellow and green He-Ne lasers

- $\mathrm{AO}$ and EO modulators

- Optical Fiber Fusion Splicer

- Optical time domain reflectometer (OTDR)

- Tunable Light Source at $1550 \mathrm{~nm}$

- Fiber Bragg gratings and other fiber optic components

- 1000 grade Cleanroom

- Different types of vacuum pumps (rotary, diffusion, turbo and cryo) and gauges

- Thermal evaporator, and E-beam evaporator

- Wet etching and dry etching facility

- Mask aligner and optical lithography

- Telescopes with GPS and other types of optical instruments

- Bio-rad FTS 60 High resolution Fourier transform infrared (FT-IR) spectrometer

- Deep level transient spectroscopy (DLTS)

- Current-voltage (I-V) capacitor-voltage (C-V) characterization

- Hall-effect measurement

- Brüker AXS High resolution $x$-ray diffraction (multidisciplinary facility)

- Spectroscopic elipsometer

- High resolution Optical microscopy

- Vacuum leak detector and residual pressure analyzer

- Atomic force microscope (AFM)

- Photonic crystal fibers 
In order to meet the needs of the local and the national industry, IUP is committed to maintaining rigor and integrity in its program. Because of the fast advance and truly interdisciplinary nature of the EO program, our teaching strategies give the activities that encourage creative thinking, critical thinking and life-long learning highest priority. Secondly, since the program is introduced early during the freshman and sophomore, we emphasize more on the perspectives of concept development and qualitative analysis rather than mathematical derivations. Thirdly, interactive learning is the hallmark of EO education. By providing a clear educational pathway for students who start their education at IUP, the program encourages the best students to continue their studies through an exciting 2+2 program with a Bachelor degree with EO track.

\section{Future development}

Since the majority of high schools offer little or no optics in K-12 curriculum (Johnson, 2002), most students receive little or no exposure to optics (Soileau, 2001). As a result, few students are aware of the ample career opportunities in this rapidly-evolving discipline. In order to promote participation of bright students in photonics-related disciplines, our EO program has sponsored a high school visitation program. The teachers and students from these schools are given a chance to experience real EO laboratories. The program has been especially beneficial to the local high schools with poor science facilities.

The 2+2+2 program we are implementing will offer IUP the opportunity to establish an integrated and seamless career and technical program in Electro-optics. It provides students the opportunity to enter the program at the beginning of their junior year in high schools. During their junior and senior years, they would co-enroll in the appropriate math and science courses and the four special courses in Electro-Optics which are PHYS 100 Prelude to Physics, EOPT 105 Computer Interfacing; EOPT 110 Geometric Optics and EOPT 125 Introduction to Electronics.

The secondary students in the program who graduate will earn an entry-level certificate in Electro-Optics. It would then permit them to transfer the certificate into one of the Electro-Optics options in IUP. The fifteen or more credits earned would permit a student to enter IUP's 2-year program with at least one semester of coursework. Upon graduation of the A.S. 2-year program, students could elect to matriculate to IUP's Main Campus to enroll in the B.S. degree in Applied Physics with a track in Electro-Optics. They would transfer 64 credits toward a 4-year degree by completing the A.S. 2-year program with the appropriate GPA. The multiple entry and exit points will provide appropriate skills for real jobs in the industry at each exit point.

To better align our program with the regional economic development vision, we believe that it is necessary to integrate nanophotonics into the core Electro-Optics curriculum, which will cover the understanding, characterization and measurement of nanostructure and nanodevices, especially their optical properties. These topics could be integrated into the existing EO curriculum: (1) scanning probe microscopy; (2) nanolithography and imaging, (3) probing local properties of nanodevices; (4) optical techniques used for map topology and particle size analyses; (5) photonic crystal fibers and semiconductor photonic crystal devices; (6) supercontinuum generation in a photonic crystal fiber; (7) photonic crystal light emitting diode; (8) 1D and 2D photonic crystal semiconductor lasers, etc. 


\section{Summary}

The new EO program was launched by IUP in 2002. The EO curriculum has been established to meet the rapid development of photonics industry in this region. In addition, a new building was completed this summer at Nor Northpointe Technology Center to host the EO program. We have successfully developed a process that allows our students to exit the program with the certificate, associate degree or bachelor degree with EO track. Most of our students graduated with associate degree from the EO program continue their studies towards 4-year Bachelor degree with either EO track, or with both EO and nanofabrication tracks. Our EO program has been successful (Sherman, 2004) from early student response and industrial endorsement. The progress has been made in the right direction; however, significant improvement is still required. One possible improvement is the integration of nanophotonics into the current EO curriculum.

\section{References}

1. Johnson, B. D. (2002); "The U.S. photonics job market: Recruiting for the future", Photonics Spectra, 36, p97-99.

2. Soileau, M. J. (2001); "Optics education: A blueprint for the 21st century", A project of OSA and SPIE, Retrieved from http://osa.org/education/k12/Final\%20Blueprint\%20Dec\%202001.pdf

3. Sherman, J. (2004) and Zhou, F.; "Observation from two years of a New Joint AAS Electro-Optics / BS - Applied Physics Program at Indiana University of Pennsylvania”, Great Lakes Photonics Symposium, Cleveland, OH, June 7-11, 2004 